\title{
The Impact of Implementing Public Bicycle Share Programs on Bicycle Crashes
}

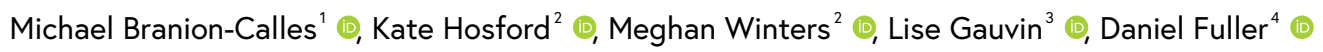

${ }^{1}$ School of Occupational and Public Health, Ryerson University, ${ }^{2}$ Faculty of Health Sciences, Simon Fraser University, ${ }^{3}$ Centre de recherche du Centre Hospitalier de l'Université de Montréal, Université de Montréal, ${ }^{4}$ School of Human Kinetics and Recreation, Memorial University of Newfoundland

Keywords: difference in differences, crashes, natural experiment, bicycling safety, bicycle share

\section{Transport Findings}

\begin{abstract}
A docked public bicycle share program (PBSP) makes bicycles available to the public. There is limited evidence on the impact of PBSPs on safety. We estimated the impacts of implementing a PBSP on the likelihood of bicycle crashes using a difference in differences approach with repeated cross-sectional survey data (selfreported crashes) collected in 8 Canadian and US cities, from 2012-2014. Relative to control cities (Detroit, Philadelphia, Vancouver), we found that the odds of reporting a bicycling crash did not change after implementing a PBSP (New York, Chicago) and were lower in cities that had existing PBSPs (Boston, Montreal, Toronto).
\end{abstract}

\section{Research Question}

A docked public bicycle share program (PBSP) make bicycles available to the public throughout a service area, and can lead to increased bicycling within a population (Fishman 2016; Hosford et al. 2018, 2019). There is currently limited evidence on the population-level impacts of PBSPs in terms of bicycling crashes and injuries (Fishman, 2016; Fishman \& Schepers, 2018; Martin et al., 2016). The International Bikeshare Impacts on Cycling and Collisions Study (IBICCS) collected data from over 20,000 participants in 8 major Canadian and US cities from 2012 - 2014 (Fuller et al., 2014). Here, we use the IBICCS data to estimate the impacts of implementing a PBSP on the likelihood of self-reporting a bicycling crash.

\section{Methods and Data}

IBICCS is a quasi-experimental non-equivalent groups study designed to evaluate the health and traffic safety impacts of PBSPs. The study protocol is published elsewhere (Fuller et al. 2014). Residents (aged 18+ years) in cities that either had implemented a new PBSP in 2013 (Chicago, New York), had an existing PBSP (Boston, Montreal, Toronto), or had no PBSP during the study period (Detroit, Philadelphia, Vancouver) were sampled. Cities with existing PBSPs included Boston (implemented 2011), Montreal (implemented 2009), and Toronto (implemented 2011) (Hosford et al. 2019). Cross-sectional data were collected in each city in the fall of 2012, 2013, and 2014. Data collected included information on bicycling behaviour, bicycling crashes, sociodemographic characteristics, and residential location.

We used a difference in differences approach to evaluate the impact of implementing PBSPs on the likelihood of reporting a bicycling incident (Fuller et al. 2013). This analysis focuses on changes in self-reported bicycling crashes 
over time for bicyclists in cities with a newly implemented PBSP, or an existing PBSP, compared to bicyclists in cities with no PBSP (control cities). We used census data to apply age and sex post-stratification weights to adjust the sample to better represent the general population. Survey weights were truncated at 0.2 and 10 (Hosford et al. 2019).

We used weighted logistic regression models to ascertain whether or not the likelihood of reporting a crash changed over time for bicyclists in a newly implemented or existing PBSP city, relative to those in control cities. To quantify the impact of implementing a PBSP on the likelihood of selfreporting a crash we used a model that includes year (2012 [baseline], 2013, 2014), city type (No PBSP [control], newly implemented PBSP, or existing PBSP) and additional covariates to adjust for characteristics of participants. We use an interaction term between year and city type to quantify the effect of PBSPs on the likelihood of a bicyclist self-reporting a crash within newly implemented or existing PBSP city, relative to those in control cities. We selected additional covariates based on bicyclist characteristic and environmental factors that have previously been identified as risk factors for a bicyclist crash (Branion-Calles et al. 2020; Degraeuwe et al. 2015; Fuller et al. 2013; Poulos et al. 2015; Tin Tin, Woodward, and Ameratunga 2013; Vanparijs et al. 2015). This included a measure of how much participants bicycle (average weekly bicycling hours in the past 30 days), age (18-24, 25-34, 35-44, 45-54, 55-64, 65+ years), sex (woman, man), educational attainment (high school or less, at least some college or university), perceived safety of bicycling (dangerous, neither safe nor unsafe, safe), and helmet use (never, seldom, often, always). We also used Walk Score ${ }^{\circledR}$ of a participants' neighbourhood as a proxy for favourability of within-city built environment conditions (Walk Score 2020).

\section{Findings}

Across cities and survey periods there were 4,484 participants (weighted total) who indicated they bicycled at least once in the previous month and provided complete data. Of these, 934 participants $(20.8 \%)$ reported at least one crash in the previous 3 months. Amongst the 934 participants who reported a crash, $38.6 \%$ indicated that the most recent crash resulted in injury and 18.6\% involved a visit to the emergency room (Table 1). The number of participants who reported bicycling in the previous month increased from 1,074 at baseline in 2012 to 1,721 at two-year follow-up in 2014 (Table 2). There was a considerable change in the perception of bicycling safety with the proportion who view bicycling as dangerous in their city decreasing from $29.9 \%$ in 2012 to $23.5 \%$ in 2014.

In the logistic regression models, the interaction term (Year $\times$ City PBSP Status) is the estimated difference in the likelihood of a bicycling crash over time in cities that have a newly implemented or existing PBSP, relative to change over time in cities without a PBSP (Table 3). Relative to the change 
Table 1. Weighted characteristics of crashes in which a participant fell of their bike in the past 3 months, pooled.

\begin{tabular}{lll}
\hline & Weighted $\mathbf{n}(\%)^{\mathrm{a}}$ \\
\hline Participants that have experienced a crashed in the past 3 months... & & $(100.0)$ \\
For any reason & 934.0 & $(32.1)$ \\
Involving a car-door & 299.4 & $(18.1)$ \\
Involving a motor vehicle & 168.9 & $(20.9)$ \\
Involving another cyclist & 195.0 & $(20.0)$ \\
Involving a pedestrian & 186.9 & $(45.1)$ \\
Involving a road hazard (tracks, pothole, curb) & 428.1 & $(35.3)$ \\
Involving personal distraction & 330.1 \\
Involving another reason not listed & 185.9 \\
In their most recent collision, participants that ... & $(19.9)$ \\
Were injured & 360.7 \\
Visited an emergency room & 174.1 & $(38.6)$ \\
Riding a bike share bicycle & 179.7 & $(18.6)$ \\
\hline
\end{tabular}

${ }^{a}$ Categories are not mutually exclusive, participants were able to select multiple reasons for a crash. As such categories will not add up to $100 \%$.

in likelihood of a crash in cities without a PBSP (and after adjustment for bicycling exposure, sociodemographic characteristics, and Walk Score), there was no statistically significant difference in the odds of reporting a bicycling crash for cities with newly implemented PBSPs after 1-year (Odds Ratio [OR]: 1.09; 95\% Confidence Interval [CI]: 0.57, 2.10), and after 2-years (OR: 1.33; 95\% CI: 0.71, 2.50). Relative to the change in the likelihood of a crash in cities without a PBSP, for cities with existing PBSPs there was a significant decrease in likelihood of a crash after 2-year follow-up (OR: 0.49; CI: 0.25, 0.98). Figure 1 illustrates the model-based estimates of changes in the predicted probability of a crash from 2012 to 2014 for participants across cities with existing, newly implemented, or no PBSPs.

In this study of population-level bicycling across 8 large cities, we observed that bicycle safety outcomes in cities with a newly implemented PBSP were no different from other cities in terms of safety. PBSPs may be associated with positive impacts on safety over longer time periods, as implied by the decreased odds of a crash in cities that had an existing PBSP at baseline. There are very few studies that evaluate the impact of PBSPs on bicycling safety outcomes. Bicycling crashes are vastly underreported in administrative data (Langley et al. 2003; Winters and Branion-Calles 2017). Although fatalities are consistently recorded, they are, fortunately, very rare (Beck, Dellinger, and O'Neil 2007; Teschke et al. 2013). The IBICCS study provided a large multi-city sample of self-reported bicycling crashes, overcoming data gaps in administrative data, and further, allowed for a quasi-experimental study. Confidence intervals were wide, limiting conclusive evidence on the impacts of implementing PBSPs on bicycling safety. 
Table 2. Weighted characteristics of bicyclists within the IBICCS sample, 2012-2014 (n weighted=4,484).

\begin{tabular}{|c|c|c|c|c|c|c|}
\hline \multirow[b]{2}{*}{ Total } & \multicolumn{2}{|c|}{$\begin{array}{l}\text { Fall } 2012 \\
\text { (Baseline) } \\
\text { weighted } n(\%)\end{array}$} & \multicolumn{2}{|c|}{$\begin{array}{l}\text { Fall } 2013 \\
\text { (1-year follow-up) } \\
\text { weighted } n(\%)\end{array}$} & \multicolumn{2}{|c|}{$\begin{array}{l}\text { Fall } 2014 \\
\text { (2-year follow-up) } \\
\text { weighted } n(\%)\end{array}$} \\
\hline & 1073.9 & $(100.0)$ & 1689.2 & $(100.0)$ & 1720.8 & $(100.0)$ \\
\hline \multicolumn{7}{|l|}{ Crash } \\
\hline No Crash & 898.4 & $(83.7)$ & 1297.5 & $(76.8)$ & 1354.1 & (78.7) \\
\hline Crash & 175.5 & $(16.3)$ & 391.7 & $(23.2)$ & 366.7 & $(21.3)$ \\
\hline \multicolumn{7}{|l|}{ City PBSP status } \\
\hline No PBSP (control) & 385.6 & $(35.9)$ & 603.3 & $(35.7)$ & 658.7 & $(38.3)$ \\
\hline Newly implemented PBSP & 237.4 & $(22.1)$ & 446.1 & $(26.4)$ & 433.0 & $(25.2)$ \\
\hline Existing PBSP & 450.9 & $(42.0)$ & 639.8 & $(37.9)$ & 629.1 & $(36.6)$ \\
\hline Total weekly bicycling hours, mean (sd) & 2.9 & $(4.7)$ & 4.2 & $(7.8)$ & 3.9 & $(7.2)$ \\
\hline Walk Score, mean (sd) & 83.8 & (19.9) & 73.0 & $(26.4)$ & 81.9 & $(21.6)$ \\
\hline \multicolumn{7}{|l|}{ Age } \\
\hline $18-24$ & 165.7 & (15.4) & 294.2 & $(17.4)$ & 314.0 & $(18.2)$ \\
\hline $25-34$ & 309.2 & $(28.8)$ & 454.5 & $(26.9)$ & 487.3 & (28.3) \\
\hline $35-44$ & 218.4 & $(20.3)$ & 285.2 & $(16.9)$ & 283.6 & $(16.5)$ \\
\hline $45-54$ & 198.5 & $(18.5)$ & 252.9 & (15.0) & 262.5 & (15.3) \\
\hline $55-64$ & 131.0 & $(12.2)$ & 309.7 & (18.3) & 254.9 & $(14.8)$ \\
\hline $65+$ & 51.1 & (4.8) & 92.7 & $(5.5)$ & 118.4 & (6.9) \\
\hline \multicolumn{7}{|l|}{ Sex } \\
\hline Women & 453.9 & $(42.3)$ & 688.3 & $(40.7)$ & 717.8 & $(41.7)$ \\
\hline Men & 620.0 & $(57.7)$ & 1001.0 & $(59.3)$ & 1003.0 & $(58.3)$ \\
\hline \multicolumn{7}{|l|}{ Education } \\
\hline High school or less & 77.4 & $(7.2)$ & 208.0 & (12.3) & 183.5 & $(10.7)$ \\
\hline College or University & 996.5 & $(92.8)$ & 1481.2 & $(87.7)$ & 1537.3 & (89.3) \\
\hline \multicolumn{7}{|l|}{ Helmet use } \\
\hline Never & 212.6 & $(19.8)$ & 310.9 & (18.4) & 326.6 & $(19.0)$ \\
\hline Seldom & 131.5 & $(12.2)$ & 168.6 & $(10.0)$ & 175.5 & $(10.2)$ \\
\hline Often & 136.5 & $(12.7)$ & 288.5 & (17.1) & 259.4 & $(15.1)$ \\
\hline Always & 593.4 & $(55.3)$ & 921.2 & $(54.5)$ & 959.3 & $(55.7)$ \\
\hline \multicolumn{7}{|l|}{ Safety perception of bicycling } \\
\hline Dangerous & 320.9 & $(29.9)$ & 358.4 & $(21.2)$ & 403.8 & $(23.5)$ \\
\hline Neither safe nor unsafe & 147.8 & $(13.8)$ & 215.3 & $(12.7)$ & 253.5 & (14.7) \\
\hline Safe & 605.2 & $(56.4)$ & 1115.5 & $(66.0)$ & 1063.5 & $(61.8)$ \\
\hline
\end{tabular}


Table 3. Weighted difference in differences logistic regression models

\begin{tabular}{|c|c|c|c|c|c|c|}
\hline & \multicolumn{3}{|c|}{ Simple ${ }^{a}$} & \multicolumn{3}{|c|}{ Adjusted $^{\mathrm{b}}$} \\
\hline & OR $(95 \% \mathrm{Cl})$ & $\mathrm{t}$ & $\mathrm{p}$-value & OR $(95 \% \mathrm{Cl})$ & $\mathrm{t}$ & $\mathrm{p}$-value \\
\hline \multicolumn{7}{|l|}{ Year $\times$ City PBSP status ${ }^{c}$} \\
\hline $2013 \times$ Newly Implemented & $1.26(0.68-2.32)$ & 0.74 & 0.46 & $1.09(0.57-2.10)$ & 0.27 & 0.79 \\
\hline $2013 \times$ Existing & $0.95(0.50-1.80)$ & -0.16 & 0.87 & $0.76(0.38-1.52)$ & -0.77 & 0.44 \\
\hline 2014 × Newly Implemented & $1.62(0.89-2.93)$ & 1.59 & 0.11 & $1.33(0.71-2.50)$ & 0.89 & 0.38 \\
\hline $2014 \times$ Existing & $0.69(0.36-1.32)$ & -1.13 & 0.26 & $0.49(0.25-0.98)$ & -2.01 & 0.04 \\
\hline \multicolumn{7}{|l|}{ Year } \\
\hline 2013 & $1.42(0.90-2.23)$ & 1.50 & 0.13 & $1.52(0.91-2.52)$ & 1.60 & 0.11 \\
\hline 2014 & $1.34(0.87-2.08)$ & 1.33 & 0.19 & $1.58(0.97-2.58)$ & 1.84 & 0.07 \\
\hline \multicolumn{7}{|l|}{ City PBSP status } \\
\hline Newly Implemented & $0.72(0.44-1.18)$ & -1.32 & 0.19 & $0.88(0.51-1.50)$ & -0.48 & 0.63 \\
\hline Existing & $1.12(0.67-1.89)$ & 0.44 & 0.66 & $1.41(0.79-2.49)$ & 1.17 & 0.24 \\
\hline
\end{tabular}

PBSP = Public bike share program; OR = Odds ratio; 95\% CI = 95\% Confidence interval

a Simple model examines interaction between Year and City PBSP status, adjusting for bicycling exposure

b Adjusted model examines interaction between Year and City PBSP status, adjusting for bicycling exposure, age, gender, educational attainment, helmet use, perceptions of bicycling safety, and Walk Score in residential neighbourhood

c Cities included in the "Newly Implemented" category include Chicago and New York (implemented PBSPs in 2013). Cities included in the "Existing" category are those that had PBSPs implemented prior to 2012 and include Boston, Montreal, and Toronto.

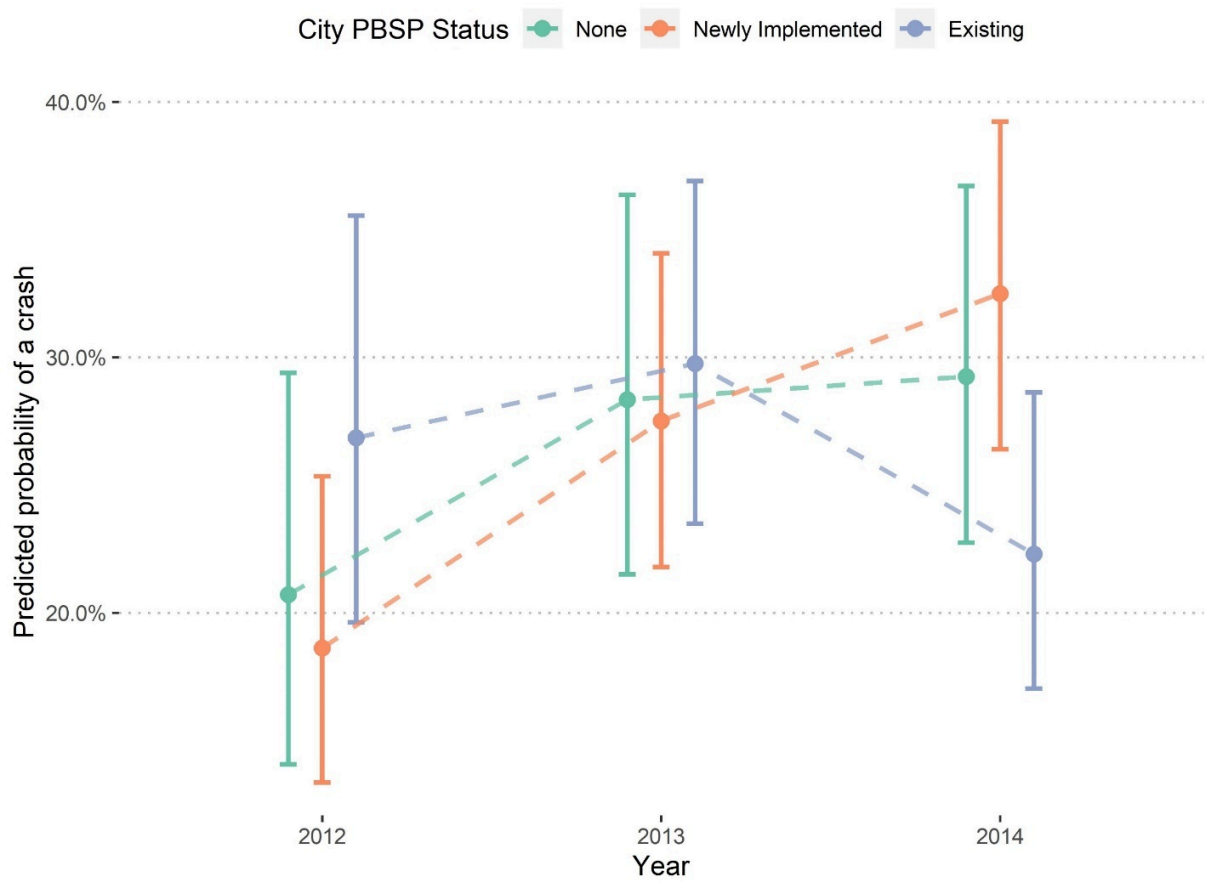

Figure 1. Predicted probability of a crash for participant defined by median of continuous covariates and mode of categorical covariates but differ in City PBSP Status and Year. PBSPs were implemented in 2013 for "Newly Implemented" cities.

This is an open-access article distributed under the terms of the Creative Commons Attribution 4.0 International License (CCBY-SA-4.0). View this license's legal deed at https://creativecommons.org/ licenses/by-sa/4.0 and legal code at https://creativecommons.org/licenses/by-sa/4.0/legalcode for more information. 


\section{REFERENCES}

Beck, L. F., A. M. Dellinger, and M. E. O’Neil. 2007. “Motor Vehicle Crash Injury Rates by Mode of Travel, United States: Using Exposure-Based Methods to Quantify Differences." American Journal of Epidemiology 166 (2): 212-18. https://doi.org/10.1093/aje/kwm064.

Branion-Calles, Michael, Thomas Götschi, Trisalyn Nelson, Esther Anaya-Boig, Ione AvilaPalencia, Alberto Castro, Tom Cole-Hunter, et al. 2020. "Cyclist Crash Rates and Risk Factors in a Prospective Cohort in Seven European Cities.” Accident Analysis Eจ Prevention 141 (June): 105540. https://doi.org/10.1016/j.aap.2020.105540.

Degraeuwe, B., Bas de Geus, I. Thomas, G. Vandenbulcke, Romain Meeusen, and Luc Int Panis. 2015. "Cycling Behaviour and Accident Risk of Utilitarian Cyclists in Belgium.” In Cycling Futures. From Research into Practice. Routledge.

Fishman, Elliot. 2016. “Bikeshare: A Review of Recent Literature.” Transport Reviews 36 (1): 92-113. https://doi.org/10.1080/01441647.2015.1033036.

Fuller, Daniel, Lise Gauvin, Anne-Sophie Dubé, Meghan Winters, Kay Teschke, Elizabeth T Russo, Andi Camden, Carol Mee, and Steven Marc Friedman. 2014. "Evaluating the Impact of Environmental Interventions across 2 Countries: The International Bikeshare Impacts on Cycling and Collisions Study (IBICCS) Study Protocol.” BMC Public Health 14 (1): 1103. https://doi.org/ 10.1186/1471-2458-14-1103.

Fuller, Daniel, Lise Gauvin, Patrick Morency, Yan Kestens, and Louis Drouin. 2013. "The Impact of Implementing a Public Bicycle Share Program on the Likelihood of Collisions and near Misses in Montreal, Canada.” Preventive Medicine 57 (6): 920-24. https://doi.org/10.1016/ j.ypmed.2013.05.028.

Hosford, Kate, Daniel Fuller, Scott A. Lear, Kay Teschke, Lise Gauvin, Michael Brauer, and Meghan Winters. 2018. "Evaluation of the Impact of a Public Bicycle Share Program on Population Bicycling in Vancouver, BC.” Preventive Medicine Reports 12 (May): 176-81. https://doi.org/ 10.1016/j.pmedr.2018.09.014.

Hosford, Kate, Meghan Winters, Lise Gauvin, Andi Camden, Anne-Sophie Dubé, Steven Marc Friedman, and Daniel Fuller. 2019. "Evaluating the Impact of Implementing Public Bicycle Share Programs on Cycling: The International Bikeshare Impacts on Cycling and Collisions Study (IBICCS)." International Journal of Behavioral Nutrition and Physical Activity 16 (1): 107. https://doi.org/10.1186/s12966-019-0871-9.

Langley, J D, N. Dow, S. Stephenson, and K. Kypri. 2003. "Missing Cyclists.” Injury Prevention 9 (4): 376-79. https://doi.org/10.1136/ip.9.4.376.

Poulos, R.G., J. Hatfield, C. Rissel, L.K. Flack, S. Murphy, R. Grzebieta, and A.S. McIntosh. 2015. "An Exposure Based Study of Crash and Injury Rates in a Cohort of Transport and Recreational Cyclists in New South Wales, Australia." Accident Analysis छ' Prevention 78 (May): 29-38. https://doi.org/10.1016/j.aap.2015.02.009.

Teschke, Kay, M. Anne Harris, Conor C. O. Reynolds, Hui Shen, Peter A. Cripton, and Meghan Winters. 2013. "Exposure-Based Traffic Crash Injury Rates by Mode of Travel in British Columbia." Canadian Journal of Public Health 104 (1): e75-79. https://doi.org/10.1007/ $\underline{\text { bf03405659. }}$.

Tin Tin, Sandar, Alistair Woodward, and Shanthi Ameratunga. 2013. "Incidence, Risk, and Protective Factors of Bicycle Crashes: Findings from a Prospective Cohort Study in New Zealand." Preventive Medicine 57 (3): 152-61. https://doi.org/10.1016/j.ypmed.2013.05.001.

Vanparijs, Jef, Luc Int Panis, Romain Meeusen, and Bas de Geus. 2015. "Exposure Measurement in Bicycle Safety Analysis: A Review of the Literature." Accident Analysis Eं Prevention 84

(November): 9-19. https://doi.org/10.1016/j.aap.2015.08.007. 
Walk Score. 2020. “Walk Score.” https://www.walkscore.com/methodology.shtml.

Winters, Meghan, and Michael Branion-Calles. 2017. "Cycling Safety: Quantifying the under Reporting of Cycling Incidents in Vancouver, British Columbia." Journal of Transport ${ }^{2}$ Health 7 (Part A): 48-53. https://doi.org/10.1016/j.jth.2017.02.010. 